\title{
Medication use in European primary care patients with lower respiratory tract infection:
}

\author{
an observational study
}

\begin{abstract}
Background

It is largely unknown what medication is used by patients with lower respiratory tract infection (LRTI).

Aim

To describe the use of self-medication and prescribed medication in adults presenting with LRTI in different European countries, and to relate self-medication to patient characteristics.

\section{Design and setting}

An observational study in 16 primary care networks in 12 European countries.

\section{Method}

A total of 2530 adult patients presenting with LRTI in 12 European countries filled in a diary on any medication used before and after a primary care consultation. Patient characteristics related to self-medication were determined by univariable and multivariable logistic regression analysis.

\section{Results}

The frequency and types of medication used differed greatly between European countries.

Overall, $55.4 \%$ self-medicated before

consultation, and $21.5 \%$ after consultation, most frequently with paracetamol, antitussives, seeking primary health care in Europe. ${ }^{1}$ It is a frequent driver for the use of a variety of medication, either prescribed by the GP or bought over the counter (OTC). ${ }^{2}$ It is doubtful whether the balance between beneficial effects and unwanted side-effects justifies the use of many of these medications.

Many patients with LRTI use antibiotics, prescribed or self-medicated lleft over from previous prescriptions, or bought OTCl, ${ }^{3}$ despite antibiotics having limited beneficial effects for most patients with LRTI. ${ }^{4}$ This overuse of antibiotics has several downsides, including development of bacterial resistance, ${ }^{5}$ side effects, ${ }^{4,6}$ and costs. ${ }^{6}$ Similarly, there is little conclusive evidence for benefits from symptomatic treatments, ${ }^{7-9}$ which are often used inappropriately ${ }^{10}$ and can cause side effects. ${ }^{7.8}$ A systematic review on the effectiveness of OTC medications for acute cough found no benefit from codeine or antihistamines. For guaifenesin and combinations of antihistamines and decongestants, available evidence is
\end{abstract} and mucolytics. Females, non-smokers, and patients with more severe symptoms used more self-medication. Patients who were not prescribed medication during the consultation self-medicated more often afterwards. Selfmedication with antibiotics was relatively rare.

\section{Conclusion}

A considerable amount of medication, often with no proven efficacy, was used by adults presenting with LRTI in primary care. There were large differences between European countries. These findings should help develop patient information resources, international guidelines, and international legislation concerning the availability of over-the-counter medication, and can also support interventions against unwarranted variations in care. In addition, further research on the effects of symptomatic medication is needed.

\section{Keywords}

antibiotics; cough; drug therapy; primary health care; respiratory tract infections; self medication.

\section{INTRODUCTION}

Lower respiratory tract infection (LRTI) is among the commonest indications for

\footnotetext{
M Hamoen, BSc, medical student;

BDL Broekhuizen, $\mathrm{PhD}, \mathrm{MD}$, assistant professor; TJM Verheij, PhD, MD, professor, University Medical Center Utrecht, Julius Center for

Health Sciences and Primary Care, Utrecht, the Netherlands. P Little, PhD, MD, professor, Primary Care Medical Group, University of Southampton Medical School, Southampton, UK. H Melbye, PhD, MD, professor, General Practice Research Unit, Institute of Community Medicine, University of Troms $\varnothing$, Troms $\varnothing$, Norway. S Coenen, PhD, MD, professor, Laboratory of Medical Microbiology, Vaccine and Infectious Diseases Institute (VAXINFECTIO), and Centre for General Practice, Department of Primary and Interdisciplinary Care Antwerp, University of Antwerp, Belgium. H Goossens, PhD, MD, professor, Laboratory of Medical Microbiology, VAXINFECTIO, University of Antwerp, Antwerp, Belgium. CC Butler, MD, FRCGP, professor.
}

inconclusive. There is limited evidence that cough symptoms are reduced by the antitussive dextromethorphan and the mucolytic bromhexine. ${ }^{8}$ A systematic review on oral and inhaled $\beta_{2}$-agonists for acute bronchitis in patients without underlying pulmonary disease found no significant benefits. ${ }^{9}$ Furthermore, use of any additional medication increases the risk of harmful interactions with other medication or disorders. With regard to costs, the Association of the European SelfMedication Industry reported that sales of non-prescribed cough and cold products in the European Union increased from 2009 to 2011, constituting €4.8 billion in 2011.11 Furthermore, in many European countries, health services or insurance companies pay for prescribed medication, ${ }^{12}$ resulting in increased costs for these organisations and the societies they serve.

Considering this, it is important to develop adequate information resources for patients with LRTI, to allow informed decision making on the use of medication and to improve self-care. There are few recent data on self-medication for common disorders such as LRTI and it is unclear how
NA Francis, PhD, MD, senior clinical research associate, Department of Primary Care and Public Health, School of Medicine, Cardiff University, Cardiff, UK, on behalf of the GRACE clinical study group (mww.grace-lrti.org).

\section{Address for correspondence}

Marleen Hamoen, Julius Center for Health Sciences and Primary Care, UMC Utrecht PO Box 85500, 3508 GA Utrecht, the Netherlands.

E-mail: hamoen.magmail.com

Submitted: 9 August 2013; Editor's response: 17 September 2013; final acceptance: 12 November 2013.

\section{QBritish Journal of General Practice}

This is the full-length article [published online 27 Jan 2014] of an abridged version published in print. Cite this article as: Br J Gen Pract 2014; DOI: 10.3399/bjgp14X677130. 


\section{How this fits in}

Lower respiratory tract infections (LRTIS) are among the main disorders for which patients use medication. Which medication is actually used by patients, and whether this is self-medicated or physicianprescribed, is largely unknown. This study shows that a lot of medication with no proven efficacy was used by patients with LRTI, obtained on prescription and self-medicated, with large variation across the European countries. Selfmedication was more frequent before than after consultation and, in addition, self-medication was inversely related to being prescribed one or more medications during the consultation.

self-medication varies between different European countries.

This study therefore aimed to investigate the use of all self-medicated and prescribed medication in patients with LRTI in primary care in 12 European countries.

\section{METHOD}

\section{Design and study population}

This was a secondary analysis of data from the European GRACE project (Genomics to Combat Resistance against Antibiotics in Community-Acquired LRTI in Europe; www.grace-(rti.org). This project includes observational and intervention studies of the presentation, management, and outcome of LRTI in primary care.

Eligible patients were aged $\geq 18$ years, and consulting with an illness where an acute or worsened cough was the main or dominant symptom, or had a clinical presentation that suggested an LRTI, with a duration of up to and including 28 days. This definition of LRTI was used because it is the formal eligibility criterion of the GRACE study protocol and corresponds with the criteria of the International Classification of Primary Care (ICPC) code for acute bronchitis/bronchiolitis (R78) in which acute cough is the main symptom. This definition has been used previously in similar studies. ${ }^{13}$ Co-presence of symptoms of an upper respiratory tract infection was allowed. The subjective assessment of the presence of LRTI was added, to include the few patients without cough as the main symptom where GPs still suspected LRTI. It had to be the first time the patient was consulting within the illness episode. Antibiotic treatment in the previous month, and pregnancy, were reasons for exclusion. Patients with comorbidity, such as asthma and chronic obstructive pulmonary disease (COPD), were not excluded. Eligible patients were invited to participate in a randomised controlled trial (RCT) comparing amoxicillin with placebo, unless they were allergic to or had a contraindication for penicillin, were suspected of having pneumonia, or refused to participate in the trial. Those patients not providing consent to participate in the trial were invited to participate in an observational study that used the same inclusion criteria, assessments, and outcome measures. The design and study population of the observational and trial part of the study have been described previously. ${ }^{14,15}$

Participating GPs aimed to recruit consecutive eligible patients from October 2007 to May 2010 in 16 primary care networks (PCNs) in 12 countries. The PCNs were: Antwerp and Ghent in Belgium; Southampton in England; Nice in France; Rotenburg in Germany; Milan in Italy; Utrecht in the Netherlands; Bialystock, Lodz, and Szczecin in Poland; Bratislava in Slovakia; Jesenice in Slovenia; Barcelona and Mataro in Spain; Jonkoping in Sweden; and Cardiff in Wales. All included patients provided written, informed consent to participate, and ethics review committees in each country approved the study.

\section{Measurements}

GPs recorded aspects of patients' history, symptoms, comorbidity ldiabetes, chronic lung disease, including COPD, and cardiovascular disease), smoking status, clinical findings, and management, including prescriptions, on a case report form. Patients completed a symptom diary each day for up to 28 days. This diary also asked about their use of health care and medication (prescribed and selfmedicated), both before and after their initial consultation.

The following patient characteristics from the case report form were used in this analysis: sex, age, current smoking, comorbidity, and severity of symptoms at consultation. For the latter, GPs asked patients for the presence or absence of 14 symptoms (cough, phlegm production, shortness of breath, wheeze, coryza, fever, chest pain, muscle aching, headache, disturbed sleep, feeling generally unwell, interference with normal activities, confusion/disorientation, and diarrhoeal, and whether these symptoms constituted no problem, a mild problem, a moderate problem, or a severe problem.

\section{Data analysis}

Non-responders to the diary were excluded from data analysis after comparison 


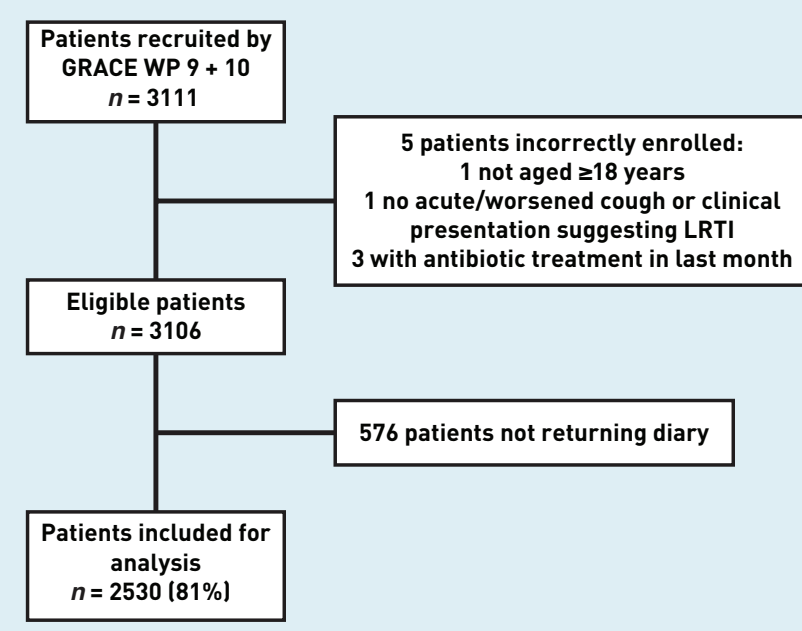

Figure 1. Flowchart of included patients.

Table 1. Characteristics of responders and non-responders to the patient diary

\begin{tabular}{|c|c|c|c|c|c|}
\hline Characteristics & $\begin{array}{l}\text { Responders, } \\
n=2530\end{array}$ & $\begin{array}{l}\text { Non-responders, } \\
\qquad n=576\end{array}$ & $\begin{array}{c}\text { Total, } \\
n=3106\end{array}$ & $P$-value & $\begin{array}{c}\text { Missing } \\
\text { values, } \boldsymbol{n}(\%)\end{array}$ \\
\hline Male sex, $n(\%)$ & $1017(40)$ & $229(40)$ & $1246(40)$ & $0.846^{a}$ & \\
\hline $\begin{array}{l}\text { Age in years, } \\
\text { mean (SD) }\end{array}$ & $51(16)$ & $45(18)$ & 50 (17) & $<0.001^{b}$ & \\
\hline $\begin{array}{l}\text { Current smoking, } \\
n(\%)\end{array}$ & 678 (27) & $193(34)$ & 871 (28) & $0.001^{\mathrm{a}}$ & $3(0)$ \\
\hline Comorbidity, ${ }^{c} n(\%)$ & 707 (28) & $150(26)$ & $857(28)$ & $0.357^{a}$ & $5(0)$ \\
\hline $\begin{array}{l}\text { Chronic lung } \\
\text { disease, } n(\%)\end{array}$ & 433 (17) & $96(17)$ & 529 (17) & $0.806^{\mathrm{a}}$ & $2(0)$ \\
\hline $\begin{array}{l}\text { Cardiovascular } \\
\text { disease, } n(\%)\end{array}$ & 238 (9) & $51(9)$ & 289 (9) & $0.685^{a}$ & $3(0)$ \\
\hline Diabetes, $n(\%)$ & 171 (7) & $29(5)$ & $200(6)$ & $0.129 a$ & $4(0)$ \\
\hline $\begin{array}{l}\text { Symptom severity } \\
\text { score, }{ }^{d} \text { mean (SD) }\end{array}$ & 37 (15) & $37(16)$ & 37 (15) & $0.658^{b}$ & $60(2)$ \\
\hline
\end{tabular}

$S D=$ standard deviation. ${ }^{\circ} \chi^{2}$ test. ${ }^{b}$ Mann-Whitney $U$ test. ${ }^{c}$ Including chronic lung disease lincluding COPD), cardiovascular disease, and diabetes. ${ }^{d}$ On a scale from 0 to 100 , including the severity of the following symptoms: cough, phlegm production, shortness of breath, wheeze, coryza, fever, chest pain, muscle aching, headache, disturbed sleep, being generally unwell, interference in normal activities, confusion/disorientation, and diarrhoea.
Use of medication was extracted from the patient diaries. The following medication groups were defined: antibiotics, antitussives, expectorants, mucolytics, antihistamine-decongestant combinations/ antihistamines, inhaled bronchodilators, inhaled corticosteroids, salicylic acid and derivatives, paracetamol/paracetamol combinations excluding psycholeptics, and non-steroidal anti-inflammatory drugs (NSAIDs). Appendix 1 shows common examples of each group.

The proportions of patients in each country using one or more medication from the different groups were determined, as well as the proportions of patients that used any of these as self-medication, before consultation and in the 28-dayfollow-up after consultation. For the use of medication before consultation, it was also determined whether patients who used antihistamines, inhaled bronchodilators, or inhaled corticosteroids had asthma or COPD, according to their medical file, as this might partly explain the use of these medications.

For the use of medication after consultation, these proportions were also determined for two subgroups: patients participating in the RCT comparing amoxicillin with placebo versus patients in the observational part of the study, because it was expected that the use of prescribed medication and selfmedication after the consultation would differ between these groups. The use of prescribed antibiotics after consultation was not analysed, since it was expected that participants in the RCT would not receive additionally prescribed antibiotics.

The associations between the variables country, sex, age, current smoking, comorbidity, and symptom severity score, and using any kind of self-medication lone or more) before the consultation las a dichotomous outcome), were measured by univariable logistic regression analysis, resulting in unadjusted odds-ratios (ORs) and 95\% confidence intervals (Cls). All variables were included as categorical variables, except for age and symptom severity score, which were included as continuous variables. In addition to the variables above, prescription of medication at consultation and participation in the trial were included as explanatory variables in the analysis of factors associated with self-medication after the consultation. Associations were considered statistically significant if the $P$-value was $<0.05$. Multivariable logistic regression analysis was carried out to obtain adjusted ORs and $95 \% \mathrm{Cls}$. 


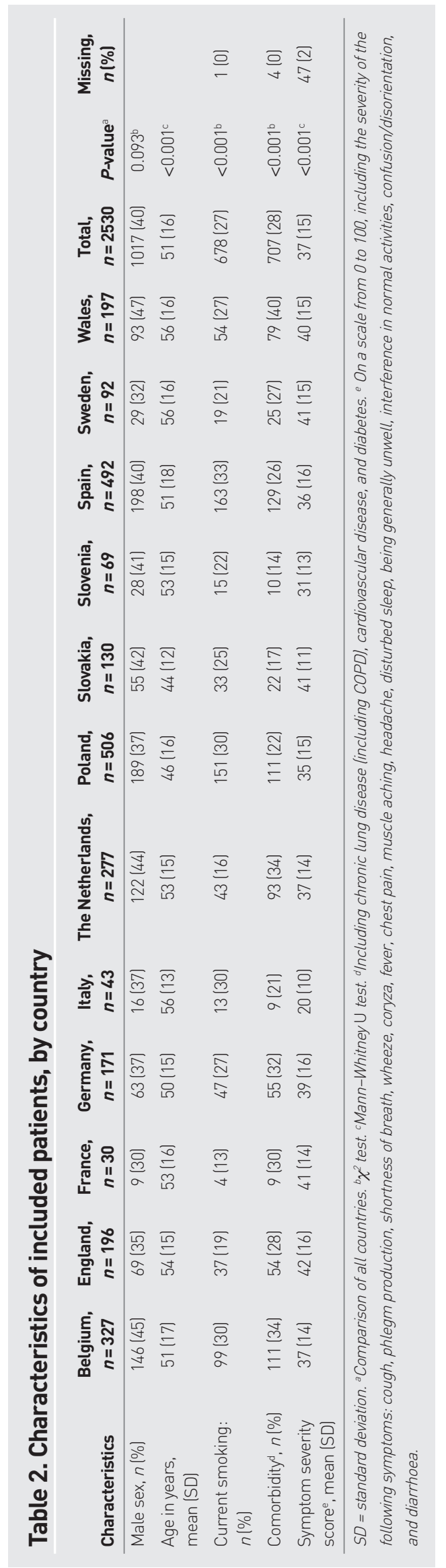

All analyses were performed in IBM SPSS Statistics (version 19).

\section{RESULTS}

A total of 294 GPs included 3106 patients (range: 1 to 82 patients per GP). The time needed to include a patient and to perform the baseline assessments was about half an hour. GPs reported that, because of this, in the busiest periods, lack of time resulted in only some of the eligible patients being recruited.

Of the 3106 included patients, 2530 (81\%) returned the patient diary and were included in the present analysis (Figure 1). Table 1 shows the characteristics of the responders and the non-responders to the patient diary. Responders were generally older than the non-responders (mean age 51 versus 45 years, $P<0.001$ ), and less often current smokers $(27 \%$ versus $34 \%$, $P=0.001$.

Table 2 shows the characteristics of the included patients in the different countries. In the overall study population, $40 \%$ were male, the mean age was 51 years (standard deviation $[S D]=16$ years), $27 \%$ were current smokers, $28 \%$ had comorbidity, and the mean symptom severity score was 37 (SD = 15). All characteristics, apart from sex, differed significantly between countries.

Table 3 shows the use of self-medication before consultation in the different countries: $55.4 \%$ of patients self-medicated with one or more drugs from the relevant medication groups before consulting the GP. The three most frequently used groups were: paracetamol (21.3\%), antitussives (15.4\%), and mucolytics (14.7\%). In general, there were large differences between countries regarding the types of medication used, and the proportion of patients that used them. Self-medication with antibiotics was self-reported in only six networks and not frequently, and was mainly seen in Italy, Belgium, and Spain. Self-medication with antitussives occurred quite frequently in all countries. Self-medication with expectorants was particularly common in Germany and England. Mucolytics were used in all countries except for England and Wales. Use of antihistamines was most common in England (18.4\%, of whom $2.8 \%$ had known asthma), Wales (12.2\%, of whom $20.8 \%$ had known asthma), and Poland $111.5 \%$, of whom $5.2 \%$ had known asthma). Self-medication with inhaled bronchodilators occurred most frequently in Spain $14.9 \%$, of whom $50.0 \%$ had known COPD or asthmal and the Netherlands $14.3 \%$, of whom $66.7 \%$ had known COPD or asthma). In Slovakia, a very high proportion 


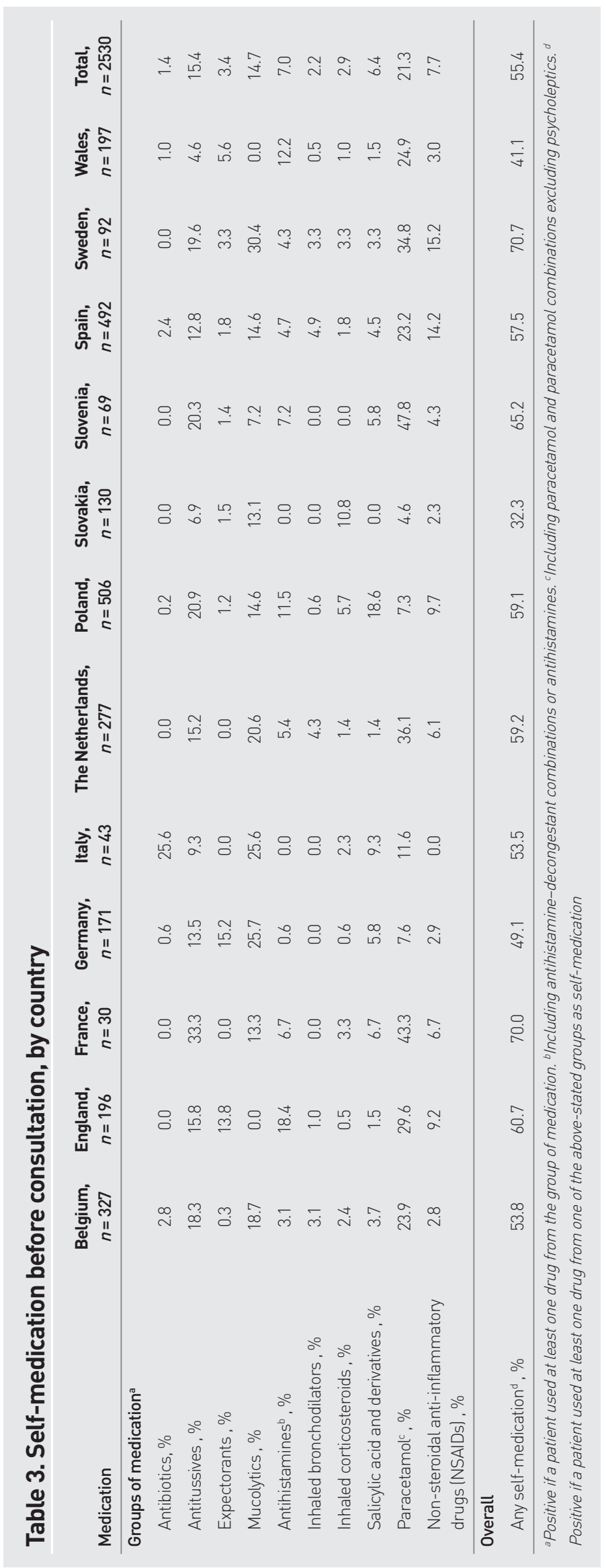

of patients self-medicated with inhaled corticosteroids $10.8 \%$, of whom none had known COPD or asthmal when compared to other countries and the overall study population $12.9 \%$, of whom $30.1 \%$ had known COPD or asthmal. Self-medication with salicylic acid was more common in Poland. Use of paracetamol varied from $47.8 \%$ (Slovenia) to $4.6 \%$ (Slovakia). Selfmedication with NSAIDs varied from 15.2\% (Sweden) to no use (Italy).

Table 4 shows the use of medication after consultation with the GP in the different countries, and for the subgroups of observational patients $(n=847)$ and trial patients ( $n=1683)$. Mucolytics (17.8\%), antitussives (17.4\%), and inhaled bronchodilators (14.6\%) were the most frequently prescribed medications used after consultation, and paracetamol (6.4\%), mucolytics (5.9\%), and antitussives $(5.4 \%)$ were most frequently used for selfmedication. In the observational group, $19.4 \%$ of the patients self-medicated with one or more drugs, compared with $22.6 \%$ in the trial group.

Of the characteristics included in univariable and multivariable logistic regression analysis, the following were independently and significantly associated with self-medication before consultation (adjusted ORs). PCN: being in the German lOR $=0.634 ; 95 \% \mathrm{Cl}=0.428$ to 0.938 ; $P=0.023$ ), Slovakian (OR $=0.296 ; 95 \%$ $\mathrm{Cl}=0.189$ to $0.463 ; P<0.0011$, or Welsh IOR $=0.474 ; 95 \% \mathrm{Cl}=0.325$ to 0.693 ; $P<0.001) P C N$, was associated with less self-medication compared to being in the Dutch PCN lused as the reference category because of representing approximately the mean proportion of self-medication). Male sex $1 \mathrm{OR}=0.730 ; 95 \% \mathrm{Cl}=0.617$ to $0.864 ; \quad P<0.001)$, and current smoking IOR $=0.756 ; 95 \% \mathrm{Cl}=0.625$ to 0.914 ; $P=0.004$ ) were also associated with less self-medication, and a higher symptom severity score $l O R=1.018 ; 95 \% \mathrm{Cl}=1.012$ to 1.024; $P<0.0011$ was associated with more self-medication. Age was significant only in the univariable analysis, and comorbidity was not significantly associated in either analysis. Detailed results can be found in Appendix 2.

With regard to self-medication after consultation, the following characteristics were independently and significantly associated (adjusted ORs): PCN; being in the Spanish $(\mathrm{OR}=0.412 ; 95 \% \mathrm{Cl}=0.269$ to 0.629; $P<0.001$ ) PCN was associated with less self-medication compared to being in the Dutch PCN. On the other hand, being in the English $\operatorname{lOR}=1.595 ; 95 \% \mathrm{Cl}=1.037$ to 


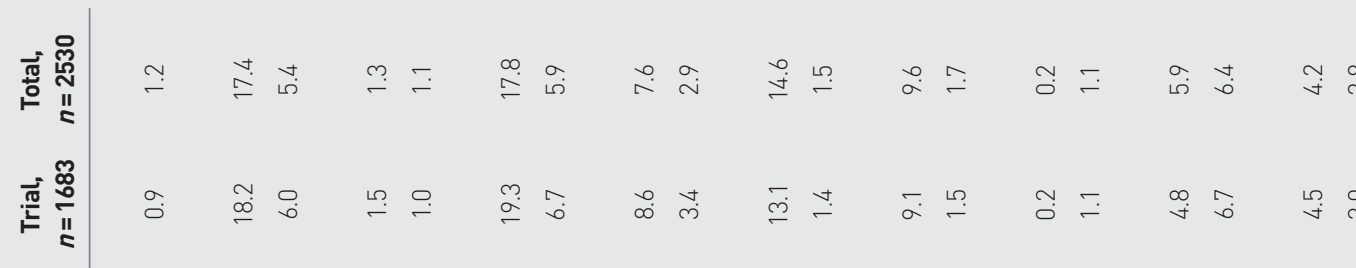

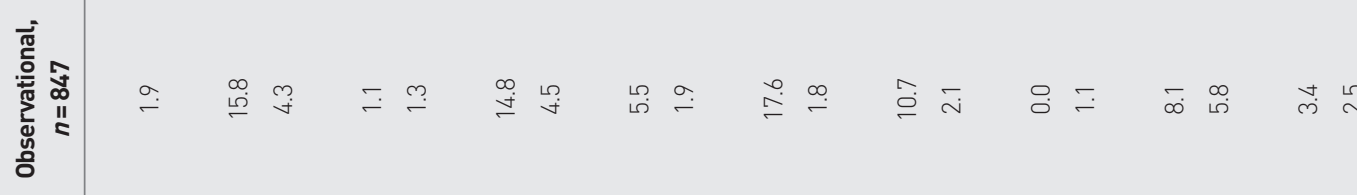

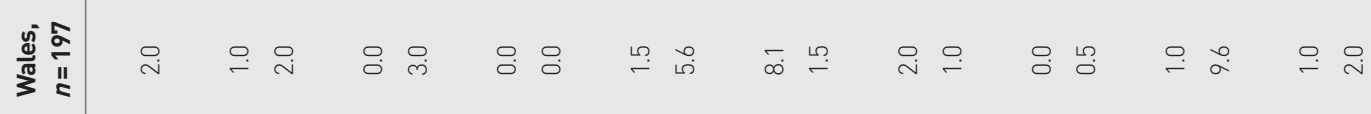

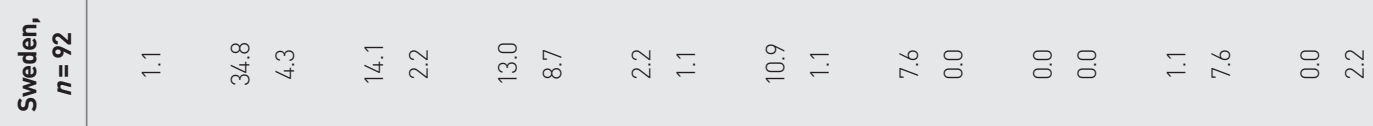

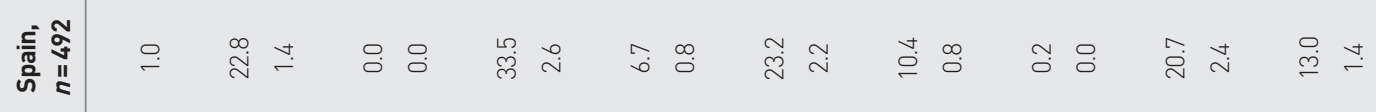

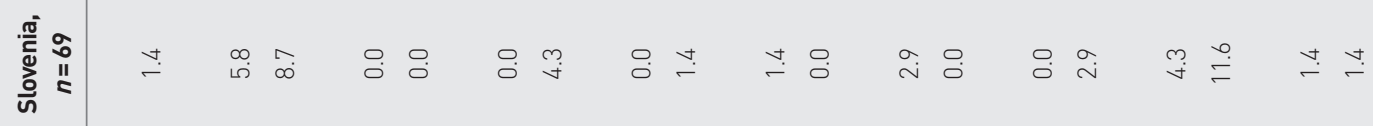

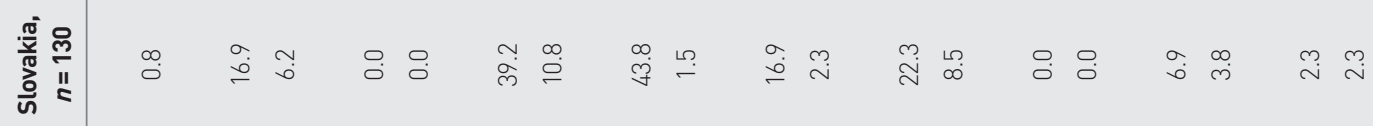

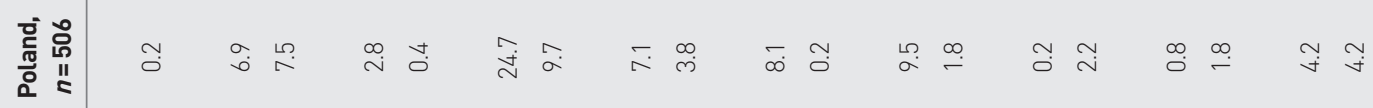

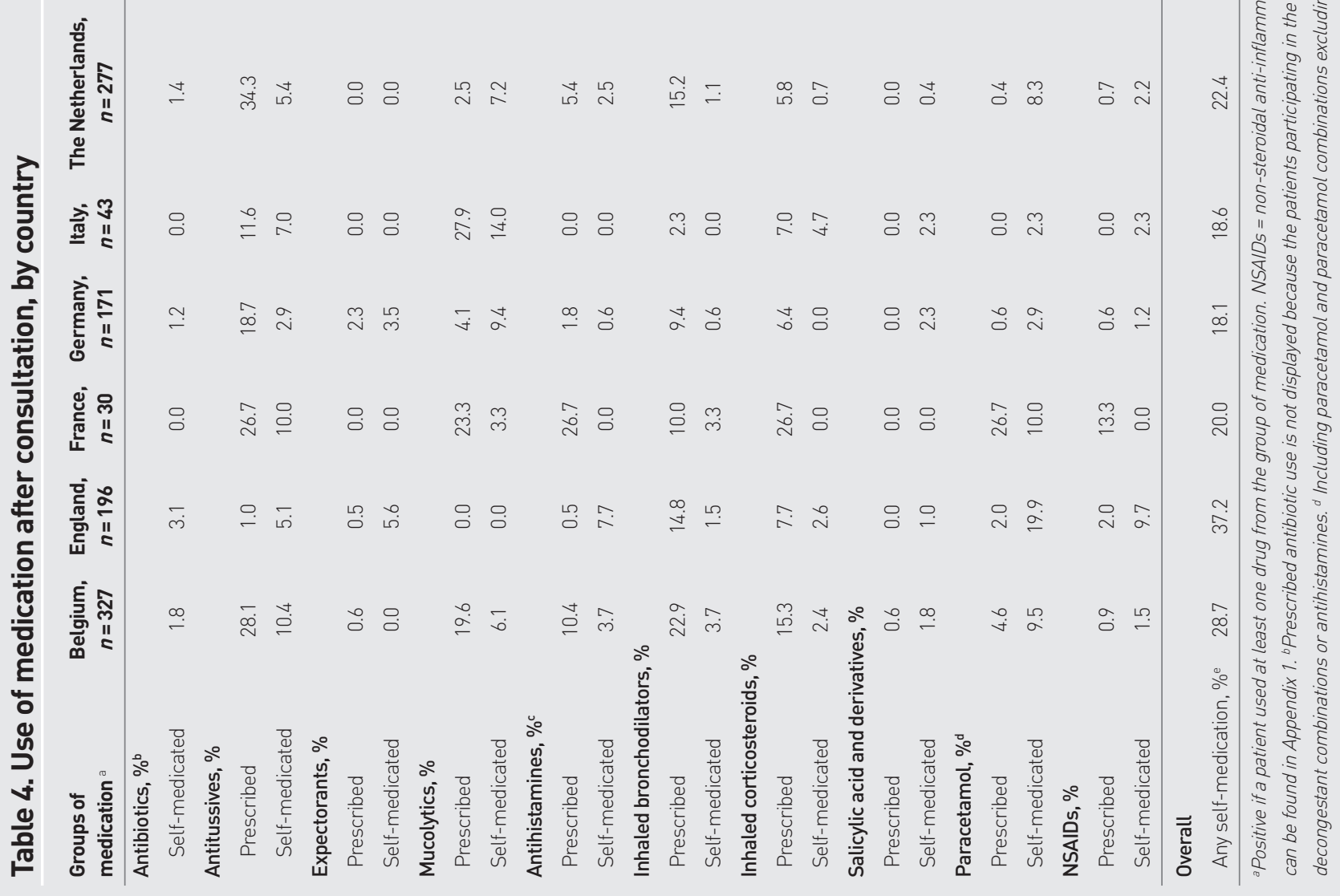


2.453; $P=0.033$ ) $P C N$ was associated with more self-medication compared to being in the Dutch PCN. Male sex $(\mathrm{OR}=0.719$; $95 \% \mathrm{Cl}=0.582$ to $0.888 ; P=0.002$ ), current smoking $(\mathrm{OR}=0.690 ; 95 \% \mathrm{Cl}=0.541$ to $0.879 ; P=0.003)$, and prescription of medication $(\mathrm{OR}=0.716 ; 95 \% \mathrm{Cl}=0.565$ to $0.907 ; P=0.006$ ) were associated with less self-medication. A higher symptom severity score $\operatorname{lOR}=1.014 ; 95 \% \mathrm{Cl}=1.007$ to 1.021 ; $P<0.001)$ was associated with more selfmedication. Again, age was only significant in the univariable analysis, and comorbidity and participation in the RCT were not significantly associated in either analysis.

\section{DISCUSSION}

\section{Summary}

A lot of medication with no proven efficacy was used by patients with LRTI, obtained on prescription and self-medicated. There was considerable variation across the different European countries. Self-medication was more frequent before than after the consultation. In addition, self-medication was inversely related to being prescribed medication during the consultation. Both before and after consultation, selfmedication was more frequent among females, non-smokers, and patients with more severe symptoms.

\section{Strengths and limitations}

The study has some important strengths. First, a large number of patients was included from primary care settings across 12 European countries. Because of the broad eligibility criteria, for example patients with comorbidity were not excluded, the authors consider the study population is representative of adults presenting with LRTI in European primary care. Second, close to complete data were received from the GPs on the baseline characteristics used in this analysis, and the response rate to the patient diary was high $(81 \%)$. The longitudinal aspect of the study, with patients filling in their diary every day, is likely to have minimised the probability of recall bias with regard to use of medication. Furthermore, the patient diaries allowed for evaluation of actual use of medication more adequately than using prescription or sales data. Finally, the combined observational and interventional research design allowed comparison of self-medication in patients participating in a randomised controlled trial and in routine practice. The authors are not aware of any previously published data on selfmedication in patients participating in a trial.
The study also has some limitations. First, the results may not be generalisable to patients with LRTI who do not visit their GP. It is known that the vast majority of patients with symptoms of respiratory tract infection do not consult their GP. ${ }^{16}$ Selfmedication, and its effectiveness for these individuals may differ from that for those who consult their GP. Secondly, not all consecutive patients were recruited. GPs reported that lack of time was by far the main limiting factor in recruiting all patients, therefore it must be acknowledged that selection took place, however the authors do not believe that this caused a clinically important selection bias. Thirdly, the data in this study were collected from PCNs, which may not be representative of all primary care patients in the whole country ffor example Catalonia in Spain). Furthermore, because of the variation in the number of patients recruited in each country, the presented results are more reliable for the countries with a higher number of patients and hence less reliable for the countries with fewer patients (for example France and Italy). Thirdly, analysis of comorbidity was limited to diabetes and cardiovascular and pulmonary disease. The association measured between comorbidity and self-medication might have been different if all comorbidity had been included. Unfortunately, it was not possible to measure the association between selfmedication and other relevant variables described in the literature, such as income, ${ }^{17}$ education, the size of the municipality of residence, ${ }^{18}$ and general health perception, ${ }^{19}$ because these data were not available.

\section{Comparison with existing literature}

As far as the authors are aware, this is the first prospective study on individual patientreported overall medication use lincluding prescribed medication and self-medication) in patients with LRTI. Available data on the frequency and types of self-medication used in the general population of European countries (Germany and Spain) show that drugs acting on the respiratory system, especially cough and cold medications, constitute a major part of all self-medication used. 18,20

With regard to variables associated with self-medication, the findings in this study are mainly consistent with previous studies on self-medication in general. ${ }^{17-19,21-24}$ More frequent self-medication among females in the present study confirms previous studies and governmental reports that consistently show that females in general use more healthcare services. ${ }^{25,26}$ This might be explained by varied health perception 
and illness behaviour between males and females, related to, for example, cultural and social elements, resulting in female patients being more likely to seek relief for their symptoms. No previous studies have reported on self-medication in smokers. It was not possible to demonstrate a relationship between self-medication and comorbidity, which previous studies did show. 18,19 This may be explained by the fact that some chronic diseases were not included in the present analyses. Interestingly, no difference was seen in selfmedication used between trial and non-trial patients.

\section{Implications for practice and research}

This study confirms assumptions that large quantities of symptomatic and, in smaller quantities, antimicrobial medications, are used by patients with LRTI presenting in primary care, and that remarkable differences exist between countries. This use of medication must be balanced against costs, side effects, and potential underdiagnosis of relevant diseases like COPD, asthma, and allergies. Many of these medications are probably not helpful and robust evidence is not available for most of the medications used. On the other hand, self-medication might be beneficial, as there is evidence that patients who consult the pharmacy first have lower GP attendance rates. ${ }^{27}$ Also, in this study, a high prevalence of asthma and/or COPD was found in patients who used inhaled bronchodilators as self-medication before consultation. This on-demand use might very well be in line with advised asthma and/or COPD action plans on medication use in case of an exacerbation, which are common in many European countries. Patients attending their GP are likely to receive an antibiotic prescription with the associated short- and long-term harms of antibiotic use, and therefore encouraging self-medication might not be beneficial. The present results indicate the need for studies on the effect and cost effectiveness of self-medicated drugs for which evidence in LRTI is lacking, to be able to provide relevant patient information. These and future findings are important not only for GPs, but also for pharmacists, who have an important role in advising their customers about purchasing and using medication.

An interesting finding was that selfmedication with antibiotics was seen in only very few patients. It should, however, be noted that the majority of patients taking antibiotics without a prescription probably did not consult their GP at all, and so would not have been eligible for recruitment into this study.

A considerable amount of self-medication and prescribed medication that has no or little proven efficacy was used by adults presenting with LRTI in primary care. This calls for further research on the beneficial and potentially harmful effects of symptomatic treatments, so that more evidence-based strategies can be used by clinicians, pharmacists, and patients. In addition, there were large unwarranted variations between European countries. The findings of this study should be considered when developing patient information resources, international guidelines about LRTI management, and international legislation concerning the availability of OTC medication.
Committee(B)(ref07/H0504/104). All the other research sites obtained ethical and competent authority approval from their local organisations. Patients fulfilling inclusion criteria were given written and verbal information and gave informed consent.

\section{Provenance}

Freely submitted; externally peer reviewed.

\section{Competing interests}

Theo JM Verheij reports research grants from Pfizer, outside of the submitted work. All other authors have declared no competing interests.

\section{Acknowledgements}

We gratefully acknowledge all participating patients, GPs, and other professionals who contributed to the GRACE study.

\section{Discuss this article}

Contribute and read comments about this article: www.bjgp.org/letters 


\section{REFERENCES}

1. Van der Linden M, Westert G, De Bakker D, Schellevis F. Tweede Nationale Studie naar ziekten en verrichtingen in de huisartspraktijk: klachten en aandoeningen in de bevolking en in de huisartspraktijk [Second National Study on diseases and interventions in general practice: symptoms and diseases in the general population and in general practice]. Utrecht/Bilthoven: NIVEL/RIVM, 2004

2. Proprietary Association of Great Britain. Annual Review 2012: securing our future health time for real engagement. London: Proprietary Association of Great Britain, 2012.

3. Grigoryan L, Haaijer-Ruskamp FM, Burgerhof JG, et al. Self-medication with antimicrobial drugs in Europe. Emerg Infect Dis 2006; 12(3): 452-459.

4. Smucny J, Fahey T, Becker L, Glazier R. Antibiotics for acute bronchitis. Cochrane Database Syst Rev 2004; (4): CD000245.

5. Goossens H, Ferech M, Vander Stichele R, Elseviers M, ESAC Project Group. Outpatient antibiotic use in Europe and association with resistance: a crossnational database study. Lancet 2005; 365(9459): 579-587.

6. Beringer PM, Wong-Beringer A, Rho JP. Economic aspects of antibacterial adverse effects. Pharmacoeconomics 1998; 13(1 Pt 1): 35-49.

7. Chang CC, Cheng AC, Chang AB. Over-the-counter (OTC) medications to reduce cough as an adjunct to antibiotics for acute pneumonia in children and adults. Cochrane Database Syst Rev 2012; (2): CD006088.

8. Smith SM, Schroeder K, Fahey T. Over-the-counter medications for acute cough in children and adults in ambulatory settings. Cochrane Database Syst Rev 2008; (1): CD001831.

9. Becker LA, Hom J, Villasis-Keever M, van der Wouden JC. Beta2-agonists for acute bronchitis. Cochrane Database Syst Rev 2011; (7): CD001726.

10. Eickhoff C, Hammerlein A, Griese N, Schulz M. Nature and frequency of drug-related problems in self-medication (over-the-counter drugs) in daily community pharmacy practice in Germany. Pharmacoepidemiol Drug Saf2012; 21(3): 254-260.

11. AESGP - Association of the European Self-Medication Industry. European selfmedication pharmaceutical market - cough and cold products. http://uww. aesgp.eu/facts-figures/market-data/\#coughandcold laccessed 25 Nov 2013).

12. Vogler S, Habl C, Bogut M, Voncina L. Comparing pharmaceutical pricing and reimbursement policies in Croatia to the European Union Member States. Croat Med J 2011; 52(2): 183-197.

13. Bont J, Hak E, Birkhoff CE, Hoes AW, Verheij TJ. Is co-morbidity taken into account in the antibiotic management of elderly patients with acute bronchitis and COPD exacerbations? Fam Pract 2007; 24(4): 317-322.
14. van Vugt SF, Broekhuizen BD, Lammens $C$, et al. Use of serum $\mathrm{C}$ reactive protein and procalcitonin concentrations in addition to symptoms and signs to predict pneumonia in patients presenting to primary care with acute cough: diagnostic study. BMJ 2013; 346: $\{2450$

15. Little P, Stuart B, Moore M, et al. Amoxicillin for acute lower-respiratory-tract infection in primary care when pneumonia is not suspected: a 12-country, randomised, placebo-controlled trial. Lancet Infect Dis 2013; 13(2): 123-129.

16. Melbye $H$, Joensen $L$, Risor MB, Halvorsen PA. Symptoms of respiratory tract infection and associated care-seeking in subjects with and without obstructive lung disease; the Tromso Study: Tromso 6. BMC Pulm Med 2012; 12: 51.

17. Johnson RE, Pope CR. Health status and social factors in nonprescribed drug use. Med Care 1983; 21(2): 225-233.

18. Figueiras A, Caamano F, Gestal-Otero JJ. Sociodemographic factors related to self-medication in Spain. Eur J Epidemiol 2000; 16(1): 19-26.

19. Nielsen MW, Hansen EH, Rasmussen NK. Prescription and non-prescription medicine use in Denmark: association with socio-economic position. Eur J Clin Pharmacol 2003; 59(8-9): 677-684.

20. Du Y, Knopf H. Self-medication among children and adolescents in Germany: results of the National Health Survey for Children and Adolescents (KiGGS). Br Clin Pharmacol 2009; 68(4): 599-608

21. Bush PJ, Rabin DL. Who's using nonprescribed medicines? Med Care 1976; 14(12): 1014-1023.

22. Al-Windi A, Elmfeldt D, Svardsudd K. The relationship between age, gender, well-being and symptoms, and the use of pharmaceuticals, herbal medicines and self-care products in a Swedish municipality. Eur J Clin Pharmacol 2000; 56(4): 311-317.

23. Beitz R, Doren M, Knopf H, Melchert HU. Self-medication with over-the-counter (OTC) preparations in Germany. Bundesgesundheitsblatt Gesundheitsforschung Gesundheitsschutz 2004; 47(11): 1043-1050.

24. Eggen AE. Patterns of medicine use in a general population ( $0-80$ years). The Influence of age, gender, diseases and place of residence on drug use in Norway. Pharmacoepidemiol Drug Saf 1997; 6(3): 179-187.

25. Bertakis KD, Azari R, Helms LJ, Callahan EJ, Robbins JA. Gender differences in the utilization of health care services. J Fam Pract 2000; 49(2): 147-152.

26. Gijsen R, Poos M. Huidig zorggebruik. In: Volksgezondheid toekomst verkenning, nationaal kompas volksgezondheid. [Dutch public health status and forecasts reporting, national public health compass]. Bilthoven: RIVM, 2012. http://www. nationaalkompas.nl/zorg/huidig-zorggebruik/ (accessed 25 Nov 2013).

27. Little P, Somerville J, Williamson I, et al. Psychosocial, lifestyle, and health status variables in predicting high attendance among adults. Br J Gen Pract 2001; 51(473): 987-994. 


\begin{tabular}{|c|c|}
\hline Groups of medication & Common example \\
\hline \multirow[t]{3}{*}{ Antibiotics } & Amoxicillin \\
\hline & Co-amoxiclav \\
\hline & Doxycycline \\
\hline \multirow[t]{3}{*}{ Antitussives } & Codeine \\
\hline & Dextromethorphan \\
\hline & Paracodeine \\
\hline \multirow[t]{3}{*}{ Expectorants } & Gelomyrtol (containing myrtol) \\
\hline & Robitussin (containing guaifenesin) \\
\hline & Buttercup cough syrup (containing squill liquid) \\
\hline \multirow[t]{3}{*}{ Mucolytics } & Acetylcysteine \\
\hline & Ambroxol \\
\hline & Bromhexin \\
\hline \multirow{3}{*}{$\begin{array}{l}\text { Antihistamine-decongestant } \\
\text { combinations or antihistamines }\end{array}$} & Loratadine \\
\hline & Cetirizine \\
\hline & Cloperastine \\
\hline \multirow[t]{3}{*}{ Inhaled bronchodilators } & Salbutamol \\
\hline & Salmeterol/fluticason \\
\hline & Formoterol/budesonide \\
\hline \multirow[t]{3}{*}{ Inhaled corticosteroids } & Beclometasone \\
\hline & Fluticason \\
\hline & Budesonide \\
\hline \multirow[t]{3}{*}{ Salicylic acid and derivatives } & Acetylsalicylic acid \\
\hline & Acetylsalicylic acid + calcium gluconate \\
\hline & Acetylsalicylic acid + ascorbic acid (vitamin C) \\
\hline \multirow{3}{*}{$\begin{array}{l}\text { Paracetamol and paracetamol } \\
\text { combinations excluding } \\
\text { psycholeptics }\end{array}$} & Paracetamol \\
\hline & Co-codamol (paracetamol and codeine phosphate) \\
\hline & Paracetamol + caffeine \\
\hline \multirow[t]{2}{*}{$\begin{array}{l}\text { Non-steroidal anti-inflammatory } \\
\text { drugs (NSAIDs) }\end{array}$} & $\begin{array}{l}\text { Ibuprofen } \\
\text { Naproxen }\end{array}$ \\
\hline & Diclofenac \\
\hline
\end{tabular}

${ }^{a}$ All generic names, except for expectorants, with common brand names and their expectorant ingredients. 


\begin{tabular}{|c|c|c|c|c|c|c|c|c|}
\hline Characteristics & $\begin{array}{l}\text { Self-medication } \\
\text { used, } n(\%)\end{array}$ & $\begin{array}{l}\text { Missing, } \\
n(\%)\end{array}$ & $\begin{array}{l}\text { OR from univariate } \\
\text { analysis }\end{array}$ & $95 \% \mathrm{Cl}$ & $P$-value & $\begin{array}{c}\text { OR from } \\
\text { multivariate analysis }\end{array}$ & is $95 \% \mathrm{Cl}$ & $P$-value \\
\hline \multicolumn{9}{|c|}{ Any self-medication ${ }^{a}$ before consultation } \\
\hline \multicolumn{9}{|c|}{ Country } \\
\hline The Netherlands (reference) & $164(59.2)$ & & & & & & & \\
\hline Belgium & $176(53.8)$ & & 0.803 & 0.581 to 1.110 & 0.184 & 0.850 & 0.607 to 1.190 & 0.344 \\
\hline England & $119(60.7)$ & & 1.065 & 0.733 to 1.547 & 0.742 & 0.995 & 0.673 to 1.471 & 0.980 \\
\hline France & $21(70.0)$ & & 1.608 & 0.710 to 3.639 & 0.255 & 1.435 & 0.629 to 3.275 & 0.391 \\
\hline Germany & $84(49.1)$ & & 0.665 & 0.453 to 0.977 & 0.037 & 0.634 & 0.428 to 0.938 & 0.023 \\
\hline Italy & $23(53.5)$ & & 0.792 & 0.416 to 1.511 & 0.480 & 1.036 & 0.531 to 2.020 & 0.917 \\
\hline Poland & $299(59.1)$ & & 0.995 & 0.739 to 1.341 & 0.975 & 1.011 & 0.743 to 1.375 & 0.946 \\
\hline Slovakia & 42 (32.3) & & 0.329 & 0.212 to 0.510 & $<0.001$ & 0.296 & 0.189 to 0.463 & $<0.001$ \\
\hline Slovenia & $45(65.2)$ & & 1.292 & 0.745 to 2.240 & 0.362 & 1.406 & 0.803 to 2.460 & 0.233 \\
\hline Spain & $283(57.5)$ & & 0.933 & 0.692 to 1.258 & 0.649 & 0.961 & 0.706 to 1.307 & 0.799 \\
\hline Sweden & 65 (70.7) & & 1.659 & 0.997 to 2.759 & 0.051 & 1.450 & 0.862 to 2.439 & 0.161 \\
\hline Wales & $81(41.1)$ & & 0.481 & 0.332 to 0.698 & $<0.001$ & 0.474 & 0.325 to 0.693 & $<0.001$ \\
\hline Male sex & $\begin{array}{l}\text { Male: } 497 \text { (48.9); } \\
\text { Female: } 905 \text { (59.8) }\end{array}$ & & 0.642 & 0.547 to 0.754 & $<0.001$ & 0.730 & 0.617 to 0.864 & $<0.001$ \\
\hline $\mathrm{Age}^{\mathrm{b}}$ & & & 0.995 & 0.990 to 0.999 & 0.027 & 0.997 & 0.991 to 1.002 & 0.225 \\
\hline Current smoking & $\begin{array}{l}\text { Yes: } 352 \text { (51.9); } \\
\text { No: } 1049(56.7)\end{array}$ & $1(0.0)$ & 0.826 & 0.692 to 0.985 & 0.033 & 0.756 & 0.625 to 0.914 & 0.004 \\
\hline Presence of comorbidity & $\begin{array}{l}\text { Yes: } 372(52.6) ; \\
\text { No: } 1029(56.6)\end{array}$ & $4(0.2)$ & 0.853 & 0.716 to 1.015 & 0.073 & 0.888 & 0.734 to 1.074 & 0.221 \\
\hline Symptom severity score ${ }^{c}$ & & 47 (1.9) & 1.016 & 1.010 to 1.021 & $<0.001$ & 1.018 & 1.012 to 1.024 & $<0.001$ \\
\hline
\end{tabular}

\begin{tabular}{|c|c|c|c|c|c|c|c|c|}
\hline \multicolumn{9}{|c|}{ Any self-medication ${ }^{a}$ after consultation } \\
\hline \multicolumn{9}{|c|}{ Country } \\
\hline The Netherlands Ireference & $62(22.4)$ & & & & & & & \\
\hline Belgium & $94(28.7)$ & & 1.399 & 0.966 to 2.026 & 0.076 & 1.451 & 0.983 to 2.141 & 0.061 \\
\hline England & $73(37.2)$ & & 2.058 & 1.373 to 3.084 & $<0.001$ & 1.595 & 1.037 to 2.453 & 0.033 \\
\hline France & $6(20.0)$ & & 0.867 & 0.339 to 2.215 & 0.765 & 0.847 & 0.328 to 2.183 & 0.730 \\
\hline Germany & $31(18.1)$ & & 0.768 & 0.475 to 1.242 & 0.282 & 0.729 & 0.439 to 1.212 & 0.223 \\
\hline Italy & $8(18.6)$ & & 0.793 & 0.350 to 1.797 & 0.578 & 0.721 & 0.293 to 1.776 & 0.478 \\
\hline Poland & $113(22.3)$ & & 0.997 & 0.702 to 1.417 & 0.987 & 1.021 & 0.708 to 1.472 & 0.912 \\
\hline Slovakia & $34(26.2)$ & & 1.228 & 0.758 to 1.990 & 0.404 & 1.166 & 0.710 to 1.914 & 0.544 \\
\hline Slovenia & $18(26.1)$ & & 1.224 & 0.667 to 2.246 & 0.514 & 1.140 & 0.609 to 2.132 & 0.682 \\
\hline Spain & $49(10.0)$ & & 0.384 & 0.255 to 0.577 & $<0.001$ & 0.412 & 0.269 to 0.629 & $<0.001$ \\
\hline Sweden & $17(18.5)$ & & 0.786 & 0.432 to 1.429 & 0.430 & 0.676 & 0.364 to 1.256 & 0.216 \\
\hline Wales & $40(20.3)$ & & 0.884 & 0.565 to 1.382 & 0.588 & 0.825 & 0.518 to 1.314 & 0.418 \\
\hline Male sex & $\begin{array}{l}\text { Male: } 181 \text { (17.8); } \\
\text { Female: } 364 \text { (24.1) }\end{array}$ & & 0.683 & 0.560 to 0.834 & $<0.001$ & 0.719 & 0.582 to 0.888 & 0.002 \\
\hline $\mathrm{Age}^{\mathrm{b}}$ & & & 0.994 & 0.988 to 1.000 & 0.038 & 0.996 & 0.990 to 1.003 & 0.255 \\
\hline Current smoking & $\begin{array}{l}\text { Yes: } 121 \text { (17.8); } \\
\text { No: } 424 \text { (22.9) }\end{array}$ & $1(0.0)$ & 0.731 & 0.584 to 0.915 & 0.006 & 0.690 & 0.541 to 0.879 & 0.003 \\
\hline Presence of comorbidity & $\begin{array}{l}\text { Yes: } 138 \text { (19.5); } \\
\text { No: } 405 \text { (22.3) }\end{array}$ & $4(0.2)$ & 0.847 & 0.682 to 1.051 & 0.132 & 0.901 & 0.712 to 1.140 & 0.385 \\
\hline Symptom severity score ${ }^{c}$ & & $47(1.9)$ & 1.015 & 1.008 to 1.021 & $<0.001$ & 1.014 & 1.007 to 1.021 & $<0.001$ \\
\hline Medication prescribed & $\begin{array}{l}\text { Yes: } 351 \text { (19.5); } \\
\text { No: } 191(26.4)\end{array}$ & $5(0.2)$ & 0.674 & 0.550 to 0.825 & $<0.001$ & 0.716 & 0.565 to 0.907 & 0.006 \\
\hline Participation in trial & $\begin{array}{l}\text { Yes: } 381 \text { (22.6); } \\
\text { No: } 164 \text { (19.4) }\end{array}$ & & 1.219 & 0.993 to 1.496 & 0.059 & 0.983 & 0.770 to 1.255 & 0.891 \\
\hline
\end{tabular}

OR = odds ratio. a Positive if a patient self-medicated one or more drugs from the groups named in Tables 3 and $4 .{ }^{b}$ For each year increase. ${ }^{c}$ For each point increase. 